\title{
Inter-Limb Jump Asymmetries and Their Association with Sport-Specific Performance in Young Male and Female Swimmers
}

\author{
Max I. Phukan ${ }^{1}$, Rohit K. Thapa ${ }^{2}(\mathbb{D})$, Gopal Kumar ${ }^{3}$, Chris Bishop ${ }^{4}\left(\mathbb{D}\right.$, Helmi Chaabene ${ }^{5,6}$ (D) \\ and Rodrigo Ramirez-Campillo ${ }^{7,8, * \mathbb{D}}$
}

1 Department of Physical Education Pedagogy, Lakshmibai National Institute of Physical Education, Gwalior 474002, India; induphukan76@gmail.com

2 Department of Sports Biomechanics, Lakshmibai National Institute of Physical Education, Gwalior 474002, India; rohitthapa04@gmail.com

3 Department of Exercise Physiology, Lakshmibai National Institute of Physical Education, Gwalior 474002, India; gopalk.kumar8@gmail.com

4 London Sport Institute, Middlesex University, The Burroughs, London NW44BT, UK; c.bishop@mdx.ac.uk

5 Faculty of Human Sciences, University of Potsdam, 14467 Potsdam, Germany; chaabanehelmi@hotmail.fr

6 High Institute of Sports and Physical Education, University of Jendouba, Kef 7100, Tunisia

7 Department of Physical Activity Sciences, Universidad de Los Lagos, Santiago 8320000, Chile

8 Centro de Investigación en Fisiología del Ejercicio, Facultad de Ciencias, Universidad Mayor, Santiago 7500000, Chile

* Correspondence: r.ramirez@ulagos.cl; Tel.: +56-951399868

check for updates

Citation: Phukan, M.I.; Thapa, R.K.; Kumar, G.; Bishop, C.; Chaabene, H.; Ramirez-Campillo, R. Inter-Limb Jump Asymmetries and Their Association with Sport-Specific Performance in Young Male and Female Swimmers. Int. J. Environ. Res. Public Health 2021, 18, 7324. https:// doi.org/10.3390/ijerph18147324

Academic Editor: Corrado Lupo

Received: 17 June 2021

Accepted: 6 July 2021

Published: 8 July 2021

Publisher's Note: MDPI stays neutral with regard to jurisdictional claims in published maps and institutional affiliations.

Copyright: (c) 2021 by the authors. Licensee MDPI, Basel, Switzerland. This article is an open access article distributed under the terms and conditions of the Creative Commons Attribution (CC BY) license (https:// creativecommons.org/licenses/by/ $4.0 /)$.

\begin{abstract}
This study aimed to examine inter-limb jump asymmetries and their association with sportspecific performance in young swimmers. Thirty-eight (male, $n=19$; female, $n=19$ ) regional/national level young swimmers (age: $12.3 \pm 1.2$ years; height: $159.6 \pm 8.2 \mathrm{~cm}$; body mass: $52.5 \pm 9.2 \mathrm{~kg}$ ) participated in this study. Inter-limb asymmetries were assessed for single-leg countermovement jump (sL CMJ) and single-leg standing long jump (sLSLJ). Sport-specific performance was evaluated using front crawl (i.e., $50 \mathrm{~m}$ and $25 \mathrm{~m}$ ) and front crawl kick (i.e., $50 \mathrm{~m}$ and $25 \mathrm{~m}$ ). The kappa coefficient revealed a "slight" level of agreement $(\mathrm{K}=0.156,0.184$, and 0.197 for female, male, and all, respectively) between the direction of asymmetry for ${ }_{\mathrm{SL}} \mathrm{CMJ}$ and ${ }_{\mathrm{SL}} \mathrm{SLJ}$, indicating that asymmetries rarely favored the same limb during both tests. A paired sample $t$-test showed a significant difference $(p=0.025)$ between asymmetry scores obtained in ${ }_{\mathrm{SL}} \mathrm{CMJ}$ and ${ }_{\mathrm{SL}} \mathrm{SLJ}$. No significant difference was found in asymmetry scores between males and females ( $p=0.099$ to 0.977$)$. Additionally, no association between asymmetry scores and sport-specific performance was observed $(p>0.05)$. Our findings highlight the independent nature of inter-limb asymmetries derived from ${ }_{\mathrm{SL}} \mathrm{CMJ}$ and ${ }_{\mathrm{SL}} \mathrm{SLJ}$ among young male and female swimmers. Further, our results suggest no association between jumping asymmetries and sport-specific performance.
\end{abstract}

Keywords: athletic performance; physical fitness; water sport; leg; lower extremity; swimming; youth sports

\section{Introduction}

Inter-limb asymmetry refers to the difference in function or performance of one limb relative to the other [1]. These limb differences may be due to the asymmetric motor demands, resulting in functional asymmetric adaptions (e.g., greater Achilles tendon stiffness on the take-off leg for long-jumpers; greater muscle mass in the dominant arm of tennis players) [2] to allow the athletes to perform within their sport [3]. Indeed, sportspecific inter-limb asymmetry is common [4]. However, larger inter-limb asymmetry may increase the risk of non-traumatic injuries among athletes [5,6]. In addition, recent studies reported larger inter-limb asymmetry to be associated with reduced physical performance 
measures in athletes (e.g., linear sprint, change of direction ability, and repeated sprint performance) [7-9], compromising technical efficiency in sports activities. Therefore, evaluating inter-limb asymmetries among athletes is crucial [10].

Previous research has reported a significant association between inter-limb asymmetry and performance in soccer and handball players [7,8]. For instance, Bishop et al. [7] found unfavorable significant associations (up to strong) between ${ }_{\mathrm{SL}} \mathrm{CMJ}$ height asymmetry and $10 \mathrm{~m}$ sprint $(r=0.54-0.87), 20 \mathrm{~m}$ sprint $(r=0.56-0.79)$, and 505 change of direction (CoD) speed $(r=0.61-0.85)$ performance in elite academy soccer players aged 15 to 20 years. Similarly, Madruga-Parera et al. [8] found unfavorable associations (moderate) between $\mathrm{SL}_{\mathrm{SL}} \mathrm{CMJ}$ height asymmetry and $8 \times 10$ repeated sprint ability $(r=0.35-0.40)$. The same authors revealed an unfavorable association (moderate) between single-leg lateral jump asymmetry, V-cut $(r=0.31)$, and CoD speed test (i.e., $2 \times 10 \mathrm{~m}$, with $180^{\circ}$ turn) $(r=0.31)$ in adolescent handball players aged 16 years. Although previous studies have shown moderate-strong associations between asymmetry and sport-specific performance, others have reported contradictory results [11,12]. Dos'Santos et al. [12] found no significant associations between jumping asymmetries (i.e., SLSLJ and single-leg triple hop asymmetry) and $\mathrm{CoD}$ speed in multisport collegiate athletes. Similarly, Loturco et al. [11] found no significant associations between vertical jump asymmetries (i.e., sL $\mathrm{CMJ}$ and single-leg squat jump) and $30 \mathrm{~m}$ linear sprint-speed, $\mathrm{CoD}$ speed (i.e., zig-zag test), and jump squat in elite female soccer players aged 23 years.

Similarly, a previous study [13] assessed water-based tethered swimming asymmetries (i.e., force production by left and right limb during front crawl) and reported a detrimental association with overall swimming performance. However, water-based assessments are expensive, complex, and time consuming. A more plausible approach would be dry land testing (e.g., CMJ, SLJ). Previous studies [14-16] reported association of dry land testing (e.g., mean propulsive power in jump-squat, leg extension, horizontal jump) with front crawl swimming performance (i.e., $25 \mathrm{~m}$ and $50 \mathrm{~m}$ ). Loturco et al. [14] reported a large association between mean propulsive power in jump-squat and $50 \mathrm{~m}$ front crawl swimming performance $(\mathrm{r}=-0.70)$. Garrido et al. [15] reported association of leg extension exercise with $25 \mathrm{~m}(\rho=-0.69)$ and $50 \mathrm{~m}(\rho=-0.62)$ front crawl performance. Marinho et al. [16] reported association between horizontal jump and $50 \mathrm{~m}(\mathrm{r}=-0.44)$ front crawl performance.

In this regard, the relationship between inter-limb asymmetry and performance measures is not yet conclusive [3], and thus warrants further investigation. Furthermore, studies have focused on unilateral jumping inter-limb asymmetries across different sports (e.g., soccer, skateboarders, cricket, basketball, badminton, tennis) and within a specific gender (i.e., either male or female) [17-22]. However, inter-limb jump asymmetry (i.e., using dry land tests such as CMJ and SLJ) among young male and female swimmers and their relationship with sport-specific performance has received little attention in the literature.

Therefore, the primary aim of this study was to examine inter-limb jump asymmetry (i.e., both vertical and horizontal) in young male and female swimmers. The second purpose was to identify the effect of inter-limb asymmetry on sport-specific performance (e.g., front crawl) in young swimmers. We hypothesized significant vertical and horizontal inter-limb jump asymmetry differences between young male and female swimmers, with an unfavorable association with sport-specific performance [13].

\section{Materials and Methods}

\subsection{Participants}

Forty-four young swimmers who regularly compete in regional/national level events initially agreed to participate in the study. Few participants were above 15 years of age (i.e., youth athletes [23]). Therefore, to obtain a more homogenous sample of young athletes, participants above 15 years old $(n=6)$ were not included. Therefore, thirty-eight young swimmers (19 males and 19 females; age: $12.3 \pm 1.2$ years; height: $159.6 \pm 8.2 \mathrm{~cm}$; 
body mass: $52.5 \pm 9.2 \mathrm{~kg}$; swimming experience: $5.4 \pm 0.8$ years) were retained. A posteriori power calculation using G*Power software (v.3.1.9.4, University of Kiel, Kiel, Germany) with $\mathrm{a}=0.05, \mathrm{n}=38$ and effect size $=0.303$ (correlation coefficient SLSLJ and $50 \mathrm{~m}$ front crawl performance) estimated power of 0.61 . All included athletes had participated in regional and/or national level competitions in the previous year; and were free of any injury in the previous six months that could limit the unilateral jump performance or swimming performance. The participants practiced multiple swimming styles. In addition, participants were engaged in multiple recreational sports activities (not more than $2 \mathrm{~h}$ /week) as a part of their training curriculum. The experimental procedure of the study was explained to participants and their parents. Thereafter, written informed consent was provided by their parents or legal guardians and participants gave their assent. The study was approved by the Lakshmibai National Institute of Physical Education (Academic/380/1317) and conducted per the protocol laid down under the declaration of Helsinki.

\subsection{Procedures}

The data collection was conducted over a month in three different swimming training centers. All participants performed $\geq 7$ familiarization sessions with the ${ }_{\mathrm{SL}} \mathrm{CMJ}$ and ${ }_{\mathrm{SL}} \mathrm{SLJ}$ tests before the collection of the data. All testing sessions were conducted outdoors. The mean temperature, humidity, and wind velocity were $22.7 \pm 1.5^{\circ} \mathrm{C}, 69.0 \pm 8.5 \%$, and $6.0 \pm 1.0 \mathrm{~km} / \mathrm{h}$, respectively. All tests were conducted between 15:00 $\mathrm{h}$ and 18:00 $\mathrm{h}$ and participants were instructed to avoid strenuous activity $24 \mathrm{~h}$ before data collection, and heavy meals or caffeinated drinks $3 \mathrm{~h}$ before data collection.

\subsection{Unilateral Jump Tests}

The two unilateral jump tests were conducted to quantify the asymmetry on both horizontal (i.e., sLSLJ) and vertical (i.e., sL CMJ) components. The tests were conducted (in the aforementioned order) after a dry land warm-up of $\sim 10 \mathrm{~min}$. The warm-up included slow jogging at $60 \%$ of self-estimated intensity, arm swings, arm rotations, forward lunges, lateral lunges, inchworm, countermovement jumps, and standing broad jumps.

The ${ }_{\mathrm{SL}} \mathrm{SLJ}$ test was conducted on the floor (concrete pool arena) with a marked tape attached. Participants were instructed to keep their non-jumping leg at the middle of the shin (i.e., medial malleolus) and jump as far as possible along the direction of the tape following a self-selected countermovement. The jumping leg was positioned with the toes just behind the $0 \mathrm{~m}$ jumping line (i.e., starting line). Trials involving swinging of the non-jumping leg before the jump were disallowed, and a new trial was conducted after a recovery period of $\sim 30 \mathrm{~s}$. The participants were instructed to jump as far as possible forward and to land on the same leg. The horizontal distance between the starting line and the heel of the landing foot was recorded to the nearest centimeter. Three trials were conducted for each leg, with $\sim 30 \mathrm{~s}$ of recovery between trials with the same leg. The average of the three trials for each leg was selected for the analysis, and asymmetry within the ${ }_{\mathrm{SL}} \mathrm{SLJ}$ test was determined as the average of left and right leg performance [1].

The ${ }_{\mathrm{SL}} \mathrm{CMJ}$ test was conducted after the $\mathrm{SL}_{\mathrm{SLJ}}$ test, with $\geq 1$ min recovery period. The ${ }_{\mathrm{SL}} \mathrm{CMJ}$ was conducted with arms akimbo. Participants were instructed to jump for maximal height, after a self-selected knee flexion angle (i.e., countermovement). The participants were instructed to keep their non-jumping leg at the middle of the shin (i.e., medial malleolus) of the jumping leg, without swinging the non-jumping leg. Jump height generated during the ${ }_{\mathrm{SL}} \mathrm{CMJ}$ was measured with a validated iOS application, My Jump 2, installed on an Apple iPad 8th generation (Apple Inc., California, USA) with a $120 \mathrm{~Hz}$ high-speed camera at a quality of $720 \mathrm{p}$. The camera was directed as low as possible facing each athlete in the frontal plane $\sim 2 \mathrm{~m}$ away to best record jump performance. Three trials were conducted for each leg, with $\geq 30 \mathrm{~s}$ of rest between trials with the same leg. The average of the three trials for each leg was selected for the analysis, and asymmetry within the ${ }_{\mathrm{SL}} \mathrm{CMJ}$ test was determined as an average of left and right leg performance [1]. 


\subsection{Asymmetry Index}

The asymmetry index was calculated using the equation ((dominant limb-non-dominant limb)/dominant limb) $\times 100$ [1], where the dominant limb was the one with the highest jump height or longest jump distance.

\subsection{Sport-Specific Swimming Tests}

On a separate day from that of the ${ }_{\mathrm{SL}} \mathrm{SLJ}$ and ${ }_{\mathrm{SL}} \mathrm{CMJ}$ tests, sport-specific swimming performance was measured through the front crawl $(25 \mathrm{~m}$ and $50 \mathrm{~m})$, and front crawl kick with push ( $25 \mathrm{~m}$ and $50 \mathrm{~m})$. A swimming-specific warm-up was performed before testing. The warm-up included $200 \mathrm{~m}$ free swim, $200 \mathrm{~m}$ kick-drill, $200 \mathrm{~m}$ free-back, $2 \times 50 \mathrm{~m}$ build-up, and $2 \times 50 \mathrm{~m}$ build-down. Front crawl tests were performed with a diving start, whereas front crawl kick with push trials involved a push-off from the wall. These testing procedures during the front crawl kick with push were intended to better assess the effect of lower limbs by minimizing the influence of hand swing during diving. The tests were conducted in a standard $50 \mathrm{~m}$ swimming pool with the $50 \mathrm{~m}$ tests conducted on the length of the pool, and the $25 \mathrm{~m}$ tests conducted on the breadth of the pool. The participants were not allowed to drift forward or backward before initiating the start during the diving start test (i.e., front crawl $25 \mathrm{~m}$ and $50 \mathrm{~m}$ ). For the dive start, the signal for the timekeeper was the movement as the swimmer's feet left the block, whereas for the water start with push-off, the swimmer's first lower limb movement was used as an indicator to start timing. The final signal for the timekeepers to stop recording timing was the moment when the first hand of the swimmer touched the wall. Two independent timekeepers were assigned to record the timing of each trial with a stopwatch. The between timekeepers intraclass correlation coefficients (ICCs) for all tests were $\geq 0.99$. After completion of each trial, swimmers were instructed to swim back slowly to the starting point at $\sim 50 \%$ of their maximal $100 \mathrm{~m}$ speed. Thereafter, a $\sim 3$ min passive recovery period was allowed. The average of two trials was used for further statistical analysis. All the tests were conducted under the supervision of qualified swimming coaches.

\subsection{Statistical Analyses}

All statistical analyses were conducted using IBM SPSS version 20 (IBM, New York, NY, USA). Data are presented as mean \pm standard deviation (SD). The assumptions of normality of the data were verified using the Shapiro-Wilk test for the parametric test, and data violating the normality assumptions (i.e., SLSLJ) were analyzed using a non-parametric test (i.e., Mann-Whitney U-test and Spearman's rho correlations). Asymmetry direction was calculated for each participant using the "IF" function, i.e., using the formula " = asymmetry score* IF(left < right,1,-1)" in Microsoft Excel, and the level of agreement (i.e., consistency) between tests (i.e., ${ }_{\mathrm{SL}} \mathrm{CMJ}$ and ${ }_{\mathrm{SL}} \mathrm{SLJ}$ ) for asymmetry direction was calculated using kappa statistics and interpreted as poor $(<0)$, slight $(0.01-0.20)$, fair $(0.21-0.40)$, moderate (0.41-0.60), substantial (0.61-0.80), and almost perfect (0.81-0.99) [24]. Test-retest reliability for performance variables (i.e., $\mathrm{SL}_{\mathrm{SLJ}} \mathrm{SL} \mathrm{CMJ}$, sport-specific swimming tests) was determined using the coefficient of variation $(\mathrm{CV}=$ (standard error of measurement $/$ subjects mean score) $\times 100$ ), and ICC (two-way random effects model). The CV values $<10 \%$ were considered acceptable [25]. The ICC between trials was interpreted as poor $(<0.5)$, moderate $(0.5-0.75)$, good (0.75-0.9), and excellent $(>0.9)$ reliability based on the lower bound of the $95 \%$ confidence interval (CI; ICC $95 \%$ CI lower bound) [26].

A paired $t$-test was used to analyze the difference between the magnitudes of asymmetry between ${ }_{\mathrm{SL}} \mathrm{SLJ}$ vs. $\mathrm{SL}_{\mathrm{C}} \mathrm{CMJ}$. An independent $t$-test and Mann-Whitney U-test were also conducted to determine the difference between asymmetry scores between males and females. Pearson's $r$ and Spearman's rho correlations were conducted to determine the relationship between asymmetry scores and swimming-specific tests. The magnitude of the correlation between test measures was interpreted as trivial $(\leq 0.1)$, small $(0.1-0.3)$, moderate (0.3-0.5), large (0.5-0.7), very large (0.7-0.9), and almost perfect (0.9-1.0) [27]. The level of significance was set at $p \leq 0.05$. 


\section{Results}

Mean test scores, inter-limb asymmetries, and reliability outcomes are presented in Table 1. All jump tests reported good-to-excellent reliability ( ICC $_{95} \%$ CI lower bound $=0.87$ to 0.93 ) and acceptable variability $(\mathrm{CV}=5.2$ to $9.6 \%$ ) (Table 1$)$. Similarly, good-to-excellent reliability $\left(\mathrm{ICC}_{95 \%} \mathrm{CI}\right.$ lower bound $=0.76$ to 0.92$)$ and almost acceptable variability $(\mathrm{CV}=5.0$ to $11.2 \%$ ) were shown when the swimmers were grouped based on gender (Table 1). All sport-specific tests reported good reliability ( $50 \mathrm{~m}$ front crawl: $\mathrm{ICC}_{95 \% \mathrm{CI}}$ lower bound $=0.82$; $25 \mathrm{~m}$ front crawl: $\mathrm{ICC}_{95 \% \mathrm{CI}}$ lower bound $=0.86 ; 50 \mathrm{~m}$ kick: $\mathrm{ICC}_{95 \% \mathrm{CI}}$ lower bound $=0.78 ; 25 \mathrm{~m}$ kick: $\mathrm{ICC}_{95 \% \mathrm{CI} \text { lower bound }}=0.79$ ).

A kappa coefficient value of 0.197 (overall), 0.184 (male) and 0.156 (female) was obtained between ${ }_{\mathrm{SL}} \mathrm{CMJ}$ and $\mathrm{SL}_{\mathrm{SLJ}}$ asymmetry direction, which shows that asymmetries rarely favored the same side between the two jump tests, indicating that limb dominance is jump test-dependent. Individual jump asymmetry data with the direction of asymmetry for both tests are presented in Figures 1 and 2.

A paired $t$-test reported a significant difference between ${ }_{\mathrm{SL}} \mathrm{CMJ}$ and ${ }_{\mathrm{SL}} \mathrm{SLJ}$ asymmetry magnitude $(p=0.025)$ with higher scores for ${ }_{\mathrm{SL}} \mathrm{CMJ}$ compared with ${ }_{\mathrm{SL}} \mathrm{SLJ}$. In addition, an independent $t$-test and Mann-Whitney $\mathrm{U}$ test reported no significant difference between males and females in ${ }_{\mathrm{SL}} \mathrm{CMJ}(p=0.099)$ and $\mathrm{SL}_{\mathrm{SLJ}}(p=0.977)$, respectively.

The correlation between jumping asymmetries and sport-specific swimming performance is presented in Table 2. No significant correlations were found between asymmetry scores and sport-specific swimming performance.

Table 1. Asymmetry scores in single-leg countermovement jump (sL CMJ) and single-leg standing long jump (sLSLJ) in young male and female swimmers.

\begin{tabular}{|c|c|c|c|c|c|}
\hline & ble & $\begin{array}{l}\text { Mean } \pm S D \\
(\mathrm{~m})\end{array}$ & Asymmetry \% & $\begin{array}{c}\text { Intraclass Correlation } \\
\text { Coefficient }(95 \% \text { CI) }\end{array}$ & $\begin{array}{l}\text { Coefficient of } \\
\text { Variation (\%) }\end{array}$ \\
\hline \multirow{4}{*}{$\begin{array}{l}\text { Overall } \\
(\mathrm{n}=38)\end{array}$} & sLCMJ (left) & $0.10 \pm 0.02$ & \multirow{2}{*}{$8.5 \pm 5.3 *$} & $0.93(0.87-0.96)$ & 9.6 \\
\hline & SLCMJ (right) & $0.10 \pm 0.03$ & & $0.95(0.91-0.97)$ & 8.0 \\
\hline & SLSLJ (left) & $1.22 \pm 0.21$ & \multirow{2}{*}{$5.7 \pm 4.5$} & $0.97(0.93-0.98)$ & 5.2 \\
\hline & SLSLJ (right) & $1.21 \pm 0.21$ & & $0.94(0.89-0.97)$ & 6.4 \\
\hline \multirow{4}{*}{$\begin{array}{c}\text { Male } \\
(n=19)\end{array}$} & sL CMJ (left) & $0.11 \pm 0.02$ & \multirow{2}{*}{$7.1 \pm 4.9$} & $0.89(0.76-0.95)$ & 9.0 \\
\hline & SL CMJ (right) & $0.11 \pm 0.02$ & & $0.94(0.86-0.97)$ & 8.0 \\
\hline & SLSLJ (left) & $1.34 \pm 0.21$ & \multirow{2}{*}{$6.0 \pm 5.6$} & $0.97(0.92-0.99)$ & 5.0 \\
\hline & SLSLJ (right) & $1.32 \pm 0.21$ & & $0.93(0.84-0.97)$ & 6.0 \\
\hline \multirow{4}{*}{$\begin{array}{l}\text { Female } \\
(\mathrm{n}=19)\end{array}$} & ${ }_{\mathrm{SL}} \mathrm{CMJ}$ (left) & $0.09 \pm 0.02$ & \multirow{2}{*}{$9.9 \pm 5.5$} & $0.93(0.85-0.97)$ & 11.0 \\
\hline & SL CMJ (right) & $0.09 \pm 0.02$ & & $0.95(0.89-0.98)$ & 8.0 \\
\hline & SLSLJ (left) & $1.09 \pm 0.12$ & \multirow{2}{*}{$5.4 \pm 3.1$} & $0.89(0.76-0.96)$ & 6.0 \\
\hline & SLSLJ (right) & $1.10 \pm 0.13$ & & $0.89(0.76-0.95)$ & 6.0 \\
\hline
\end{tabular}

CI: confidence interval; m: meter; SD: standard deviation; * significant difference with $\mathrm{SL}_{\mathrm{SLJ}}$ asymmetry at $p=0.025$.

Table 2. Correlation coefficient between asymmetry scores and swimming performance.

\begin{tabular}{|c|c|c|c|c|c|}
\hline \multicolumn{2}{|c|}{ Asymmetry \% } & $50 \mathrm{~m}$ Front Crawl & 25 m Front Crawl & $50 \mathrm{~m}$ Kick & $25 \mathrm{~m}$ Kick \\
\hline Overall & ${ }_{\mathrm{SL}} \mathrm{CMJ}$ & 0.296 & 0.247 & 0.087 & -0.007 \\
\hline$(\mathrm{n}=38)$ & $\mathrm{SL}^{\mathrm{SLJ}}$ & $0.303^{\rho}$ & $0.285^{\rho}$ & $-0.011^{\rho}$ & $0.023^{\rho}$ \\
\hline Male & ${ }_{\mathrm{SL}} \mathrm{CMJ}$ & 0.361 & 0.288 & 0.016 & 0.135 \\
\hline$(\mathrm{n}=19)$ & SLSLJ & $0.321^{\rho}$ & $0.268^{\rho}$ & $0.032^{\rho}$ & $0.230^{\rho}$ \\
\hline Female & ${ }_{\mathrm{SL}} \mathrm{CMJ}$ & 0.144 & 0.168 & 0.244 & -0.149 \\
\hline$(\mathrm{n}=19)$ & SLSLJ & 0.330 & 0.265 & 0.016 & 0.311 \\
\hline
\end{tabular}

$\rho$ : denotes Spearman's rho (i.e., non-parametric test) correlations. sL CMJ: single-leg countermovement jump; sLSLJ: single-leg standing long jump. 


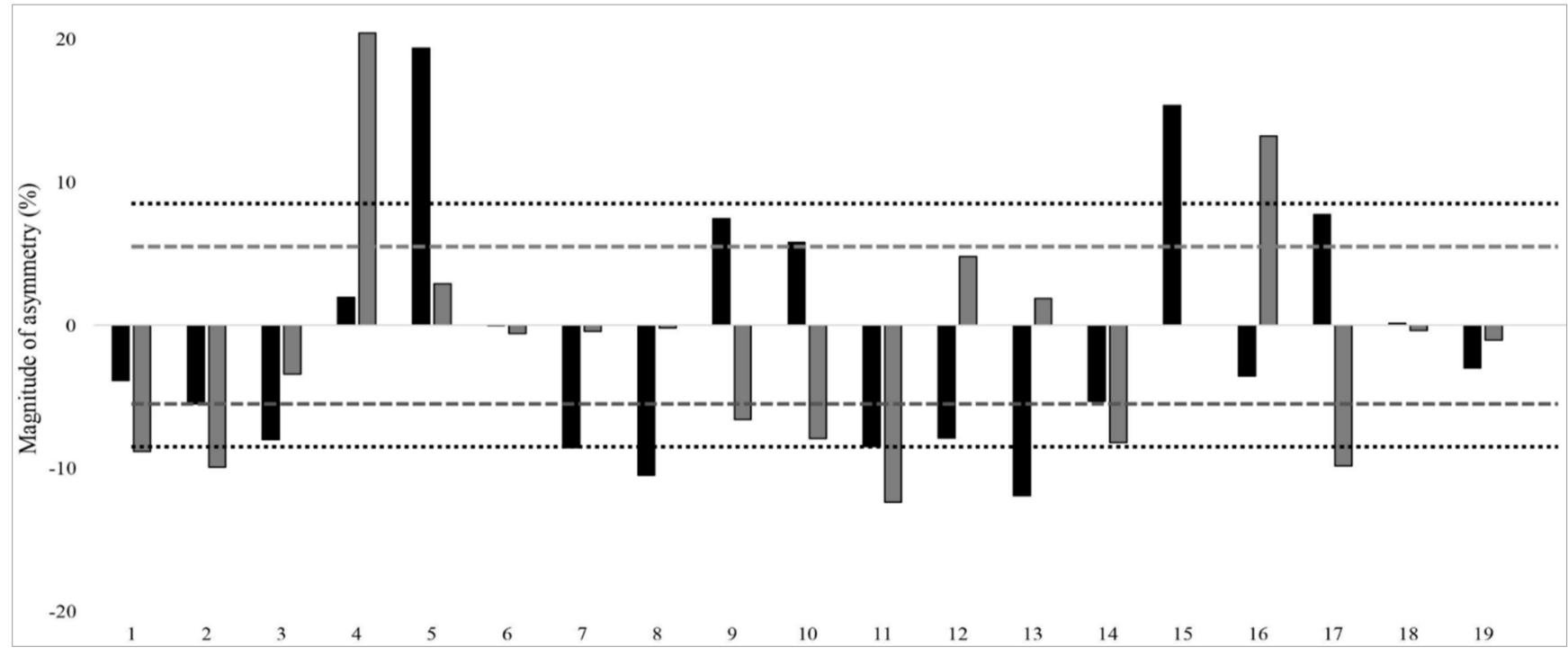

Figure 1. Inter-individual single-leg countermovement jump ( ${ }_{\mathrm{L}} \mathrm{CMJ}$ ) and single-leg standing long jump (SL SLJ) asymmetry

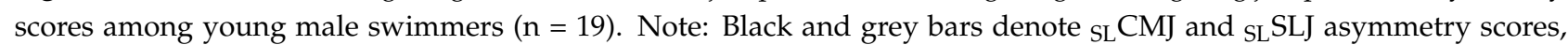
respectively. Score above and below 0 indicates asymmetry is favored on the right and left leg, respectively. Round and squared dotted lines indicate the average coefficient of variation for ${ }_{\mathrm{SL}} \mathrm{CMJ}(8.5 \%)$ and ${ }_{\mathrm{SL}} \mathrm{SLJ}(5.5 \%)$, respectively.

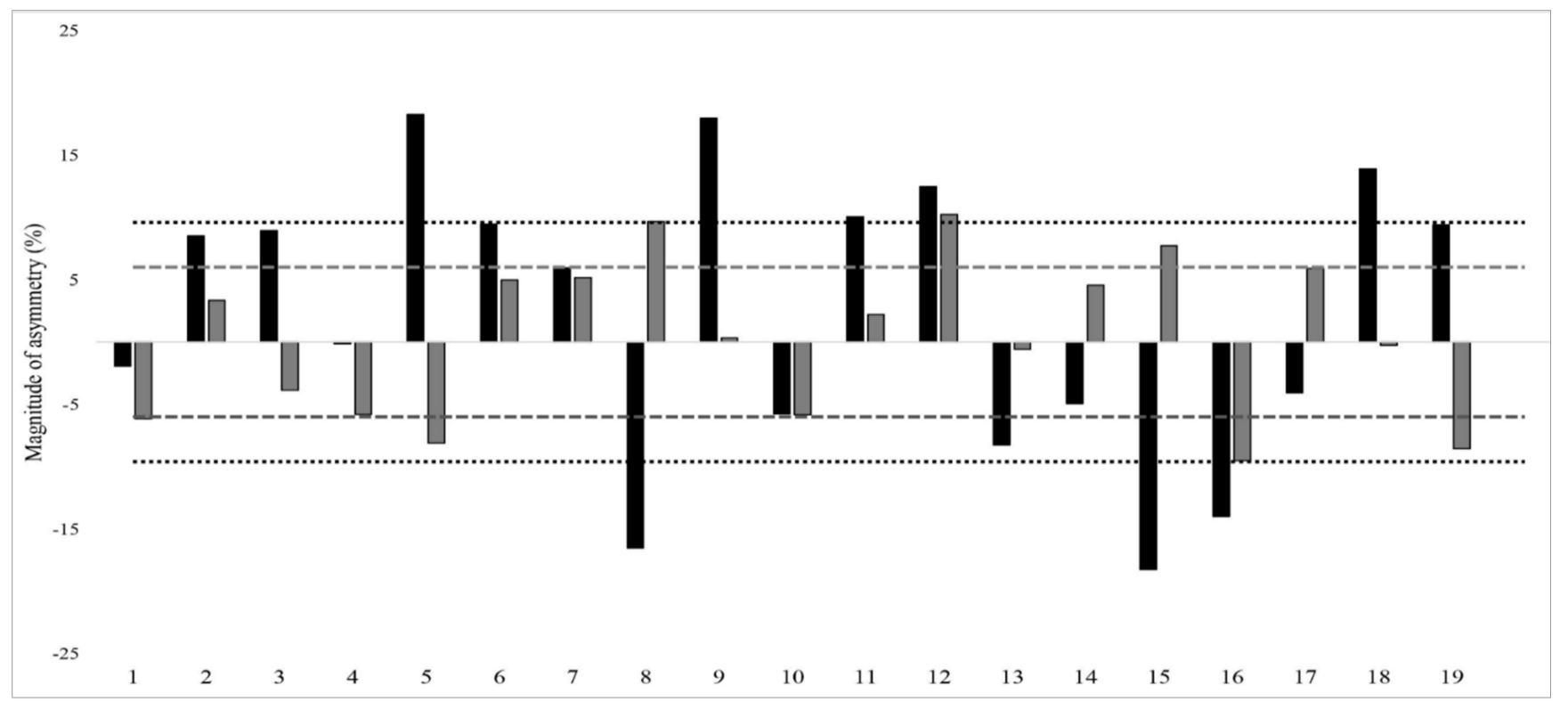

Figure 2. Inter-individual single-leg countermovement jump ( ${ }_{\mathrm{L}} \mathrm{CMJ}$ ) and single-leg standing long jump (sL SLJ) asymmetry scores among young female swimmers $(n=19)$. Note: Black and grey bars denote ${ }_{S L}$ CMJ and SLSLJ asymmetry scores, respectively. Score above and below 0 indicates asymmetry is favored on the right and left leg, respectively. Round and squared dotted lines indicate the average coefficient of variation for ${ }_{\mathrm{SL}} \mathrm{CMJ}(9.5 \%)$ and $\mathrm{SL}_{\mathrm{SLJ}}(6 \%)$, respectively.

\section{Discussion}

This study aimed to (i) examine inter-limb jump asymmetries using ${ }_{\mathrm{SL}} \mathrm{CMJ}$ and $\mathrm{SL}_{\mathrm{SLJ}}$, and (ii) investigate the effect of inter-limb asymmetries on sport-specific swimming performance (e.g., front crawl) in young male and female swimmers. The main findings showed no significant difference in the magnitude of asymmetry between males and females. In addition, results showed no association between jumping-based asymmetries and sportspecific swimming performance in young swimmers. Further, the asymmetries rarely favored the same side between vertical (sL CMJ) and horizontal (sLSLJ) jumping tests. 
When asymmetry scores of all participants were considered, there was a significantly larger asymmetry in the ${ }_{\mathrm{SL}} \mathrm{CMJ}$ than ${ }_{\mathrm{SL}} \mathrm{SLJ}$. This finding is in line with previous studies $[8,9,28]$. Lockie et al. [28] reported larger inter-limb differences for the ${ }_{\mathrm{SL}} \mathrm{CMJ}(10.4 \%)$ than for ${ }_{\mathrm{SL}} \mathrm{SLJ}(3.3 \%)$ in male team sport athletes aged 23 years. Additionally, Bishop et al. [9] conducted a study of elite youth female soccer players and reported significantly larger asymmetries for ${ }_{\mathrm{SL}} \mathrm{CMJ}(12.5 \%)$ than for ${ }_{\mathrm{SL}} \mathrm{SLJ}(6.8 \%)$. Similar observations were shown by Madruga-Parera et al. [8], who reported larger asymmetry for ${ }_{\mathrm{SL}} \mathrm{CMJ}(11.2 \%)$ than SLSLJ $(6.4 \%)$ in adolescent male handball players aged 16 years. Furthermore, a previous study in elite youth female soccer players aged 10 years by McCubbine et al. [29] suggested that $\mathrm{SL}_{\mathrm{SL}} \mathrm{CMJ}\left(\mathrm{ICC}_{95 \% \mathrm{CI}}\right.$ lower bound $=98$ both right and left leg) affords higher accuracy at detecting asymmetries compared with ${ }_{\mathrm{SL}} \mathrm{SLJ}\left(\mathrm{ICC}_{95 \% \mathrm{Cl} \text { lower bound }}=0.40-0.48\right)$ due to its ability to expose greater inter-limb asymmetries and stronger reliability than the horizontal tests. Overall, although our findings indicate that both ${ }_{\mathrm{SL}} \mathrm{CMJ}$ and ${ }_{\mathrm{SL}} \mathrm{SLJ}$ tests may be a useful (and reliable) option for practitioners for quantifying limb differences for young swimmers aged 10 to 15 years, sL CMJs and SLSLJs should not be used interchangeably.

Bishop [30] also suggested that the "direction of asymmetry" in conjunction with its magnitude could help in understanding which limb performed better as an absolute positive value of asymmetry would fail to identify the same. Therefore, the "asymmetry direction" method is used to identify consistency (i.e., by using the kappa coefficient method [31]) of jumping asymmetries favoring the same side (i.e., left vs. right) between different tests $[8,32,33]$. Our results show only a "slight" level of agreement (kappa $=0.197)$ for the consistency of asymmetry direction between ${ }_{S L} C M J$ and ${ }_{S L}$ SLJ among young swimmers, which is in agreement with previous studies [8,32,33]. Madruga-Parera et al. [8] detected "poor" to "slight" levels of agreement between ${ }_{\mathrm{SL}} \mathrm{CMJ}$, SLSLJ, and single-leg lateral jump in male adolescents handball players aged 16 years. Similarly, Loturco et al. [33] detected no inter-relationships between asymmetries calculated from isokinetic dynamometry, tensiomyography, CMJ, and squat jumps. Further, Bishop et al. [32] detected a "slight" level of agreement when reporting side consistency of peak force asymmetries between ${ }_{\mathrm{SL}} \mathrm{CMJ}$ and ${ }_{\mathrm{SL}} \mathrm{SLJ}$. Therefore, the findings of our study further support the task-specific nature of asymmetries and thus practitioners should not solely depend on one screening method for assessing asymmetry. Indeed, a more pragmatic approach would be to interpret both vertical and horizontal jump test results as separate entities. In addition, a previous study by West et al. [34] also reported different peak vertical (1541 $\pm 306 \mathrm{~N})$ and horizontal force $(809 \pm 223 \mathrm{~N})$ during a freestyle sprint start, and showed its association with $15 \mathrm{~m}$ swim-start performance, thereby confirming the necessity of both vertical and horizontal assessments for swimmers.

Our findings also showed no significant association of inter-limb jump asymmetries with swimming sport-specific performance. Although this is the first study to examine the association of dry land jump asymmetry and swimming performance in young athletes of both sexes, two previous studies assessed asymmetry using a tethered swimming test (i.e., using strain gauge) and reported similar [35] and contradicting [13] findings to ours. Morouço et al. [35] analyzed asymmetries during front crawl tethered swimming and reported no association of inter-limb asymmetries with short-sprint swimming performance. In contrast, Dos Santos et al. [13] examined asymmetries during front crawl tethered swimming and reported that an increase in inter-limb differences in force production may be detrimental to overall swimming performance. Of note, unlike our study, the aforementioned studies [13,35] assessed asymmetry during a static swimming test and quantified asymmetry via the force produced by each segment (i.e., right or left) during the swimming test. Considering the practical aspects associated with dry land ${ }_{\mathrm{SL}} \mathrm{CMJ}$ and ${ }_{\mathrm{SL}} \mathrm{SLJ}$ asymmetry tests, future studies may consider examining its association with swimming-specific asymmetry test (i.e., using a tethered swimming test).

Similar to our findings, no association of jumping asymmetries and performance measures (e.g., linear sprints, CoD) were found in soccer, handball, and multi-sport collegiate athletes [8,11,12]. Dos'Santos et al. [12] reported no association of single-leg hop 
and single-leg triple hop with the modified 505 agility test $(r=0.22$ to -0.29$)$, and $90^{\circ}$ cutting task ( $r=-0.08$ to 0.35 ) among male collegiate team sport athletes (i.e., soccer, rugby, and cricket) aged 22 years. Loturco et al. [11] also found no association of inter-limb jump asymmetries (i.e., ${ }_{\mathrm{SL}} \mathrm{CMJ}$ and single-leg squat jump) and performance measures $(5,10$, 20 , and $30 \mathrm{~m}$ linear sprint, zigzag $\mathrm{CoD}$, and muscle power test using the jump squat) in elite female soccer players aged 23 years. Madruga-Parera et al. [8] also reported no association of ${ }_{\mathrm{SL}} \mathrm{CMJ}$ and $\mathrm{SL}_{\mathrm{SLJ}}$ with $20 \mathrm{~m}$, CoD with $180^{\circ}$ turns, and $\mathrm{CoD}$ with $45^{\circ}$ turns in male adolescent handball players aged 16 years. The lack of association between jump asymmetries and performance in our study may be related to the fact that swimmers perform symmetric movement of the limbs. Continued participation in swimming might have developed the ability to maintain alignment by refining actions such as propulsion, breathing, recovery, and entry [36], thereby minimizing the effects of limb asymmetry during jumps in swimming-specific performance.

Further, meaningful asymmetries were found in our study. It is possible that these findings may relate to the age of the swimmers (10-15 years), who are still in their growth and developmental stages. Similar meaningful asymmetries were observed in male youth handball players aged 16 years (i.e., SLCMJ and ${ }_{\mathrm{SL}}$ SLJ asymmetry $=11.2 \pm 8.4 \%$ and $8.3 \pm 7.5 \%$, respectively) and basketball athletes aged 18 years ( ${ }_{\mathrm{sL}} \mathrm{CMJ}$ asymmetry $=10.6 \pm 8.6 \%$ ) $[8,22]$. The asymmetry scores for individual athletes in ${ }_{\mathrm{SL}} \mathrm{CMJ}$ and ${ }_{\mathrm{SL}} \mathrm{SLJ}$ tests are presented in Figures 1 and 2, with dotted lines indicating the CV for each test. The relevance of this $\mathrm{CV}$ for each test is that when asymmetry scores surpass the $\mathrm{CV}$, the imbalances are greater than the test variability and can be considered to be real $[1,37]$. The individual asymmetry scores were greater than the $\mathrm{CV}$ among 15 swimmers and 19 swimmers in ${ }_{\mathrm{SL}} \mathrm{CMJ}$ and ${ }_{\mathrm{SL}} \mathrm{SLJ}$, respectively. Therefore, $\leq 50 \%$ of the swimmers had real inter-limb differences during unilateral jump testing. Further studies may consider investigating how such results are modified as athletes mature and their interaction with training.

Some limitations are acknowledged in our study. Firstly, only young athletes $\leq 15$ years were included in the study. Therefore, the study results are not conclusive for $>15$ year old athletes (i.e., more mature youths or those who are no longer in the growth phase). Secondly, the swimming-specific tests were conducted only on short distances (i.e., $25 \mathrm{~m}$ and $50 \mathrm{~m}$ ). Therefore, future studies including longer distances are encouraged. Thirdly, the power obtained in the study was low (i.e., 0.61 ); therefore, future research should include larger sample size. Finally, the inter-limb asymmetry was evaluated in a single session, not in multiple sessions as previously recommended [38]. Future research should evaluate inter-limb asymmetry in multiple sessions to ensure direction of asymmetry favors the same limb.

\section{Conclusions}

The findings highlight the independent nature of inter-limb asymmetries derived from ${ }_{\mathrm{SL}} \mathrm{CMJ}$ and ${ }_{\mathrm{SL}} \mathrm{SLJ}$ among young male and female swimmers. Further, our results suggest no association between jumping asymmetries and sport-specific performance.

Author Contributions: Conceptualization, M.I.P. and R.K.T.; methodology, R.K.T.; software, R.K.T.; validation, R.K.T., C.B., H.C., R.R.-C.; formal analysis, R.K.T.; investigation, M.I.P., R.K.T. and G.K.; writing—original draft preparation, M.I.P., R.K.T. and G.K.; writing-review and editing, C.B., H.C. and R.R.-C.; supervision, R.K.T.; project administration, R.K.T. All authors have read and agreed to the published version of the manuscript.

Funding: This research received no external funding.

Institutional Review Board Statement: The study was conducted according to the Declaration of Helsinki and was approved by the Lakshmibai National Institute of Physical Education (Academic/380/1317).

Informed Consent Statement: Informed consent forms were obtained from the parents/legal guardian of the subjects involved in the study. 
Data Availability Statement: The datasets generated and analyzed for this study can be obtained from the corresponding author.

Acknowledgments: The authors feel obliged and thankful for the support of Atikur Rahman, Babul Gurung, Harekrishna Gogoi, and Mrinal Basumatary for their assistance during the data collection. The authors would also like to acknowledge the support received from Jorhat Swimming Society and Sibsagar Swimming Society.

Conflicts of Interest: The authors declare no conflict of interest.

\section{References}

1. Bishop, C.; Read, P.; Lake, J.; Chavda, S.; Turner, A. Interlimb Asymmetries: Understanding How to Calculate Differences From Bilateral and Unilateral Tests. Strength Cond. J. 2018, 40, 1-6. [CrossRef]

2. Bayliss, A.J.; Weatherholt, A.M.; Crandall, T.T.; Farmer, D.L.; McConnell, J.C.; Crossley, K.M.; Warden, S.J. Achilles tendon material properties are greater in the jump leg of jumping athletes. J. Musculoskelet. Neuronal Interact. 2016, 16, 105-112.

3. Maloney, S.J. The Relationship Between Asymmetry and Athletic Performance: A Critical Review. J. Strength Cond. Res. 2019, 33, 2579-2593. [CrossRef] [PubMed]

4. Bussey, M.D. Does the demand for asymmetric functional lower body postures in lateral sports relate to structural asymmetry of the pelvis? J. Sci. Med. Sport 2010, 13, 360-364. [CrossRef]

5. Chalmers, S.; Fuller, J.T.; Debenedictis, T.A.; Townsley, S.; Lynagh, M.; Gleeson, C.; Zacharia, A.; Thomson, S.; Magarey, M. Asymmetry during preseason Functional Movement Screen testing is associated with injury during a junior Australian football season. J. Sci. Med. Sport 2017, 20, 653-657. [CrossRef] [PubMed]

6. Fort-Vanmeerhaeghe, A.; Milà-Villarroel, R.; Pujol-Marzo, M.; Arboix-Alió, J.; Bishop, C. Higher Vertical Jumping Asymmetries and Lower Physical Performance are Indicators of Increased Injury Incidence in Youth Team-Sport Athletes. J. Strength Cond. Res. 2020. [CrossRef]

7. Bishop, C.; Brashill, C.; Abbott, W.; Read, P.; Lake, J.; Turner, A. Jumping Asymmetries Are Associated With Speed, Change of Direction Speed, and Jump Performance in Elite Academy Soccer Players. J. Strength Cond. Res. 2019. [CrossRef] [PubMed]

8. Madruga-Parera, M.; Bishop, C.; Read, P.; Lake, J.; Brazier, J.; Romero-Rodriguez, D. Jumping-based Asymmetries are Negatively Associated with Jump, Change of Direction, and Repeated Sprint Performance, but not Linear Speed, in Adolescent Handball Athletes. J. Hum. Kinet. 2020, 71, 47-58. [CrossRef]

9. Bishop, C.; Read, P.; McCubbine, J.; Turner, A. Vertical and Horizontal Asymmetries Are Related to Slower Sprinting and Jump Performance in Elite Youth Female Soccer Players. J. Strength Cond. Res. 2021, 35, 56-63. [CrossRef]

10. Dos'Santos, T.; Thomas, C.; Jones, P.A. Assessing Interlimb Asymmetries: Are We Heading in the Right Direction? Strength Cond. J. 2021, 43, 91-100. [CrossRef]

11. Loturco, I.; Pereira, L.A.; Kobal, R.; Abad, C.C.C.; Rosseti, M.; Carpes, F.P.; Bishop, C. Do asymmetry scores influence speed and power performance in elite female soccer players? Biol. Sport. 2019, 36, 209-216. [CrossRef] [PubMed]

12. Dos'Santos, T.; Thomas, C.; Jones, A.P.; Comfort, P. Asymmetries in single and triple hop are not detrimental to change of direction speed. J. Trainol. 2017, 6, 35-41. [CrossRef]

13. Dos Santos, K.B.; Pereira, G.; Papoti, M.; Bento, P.C.; Rodacki, A. Propulsive force asymmetry during tethered-swimming. Int. J. Sports Med. 2013, 34, 606-611. [CrossRef] [PubMed]

14. Loturco, I.; Barbosa, A.C.; Nocentini, R.K.; Pereira, L.A.; Kobal, R.; Kitamura, K.; Abad, C.C.; Figueiredo, P.; Nakamura, F.Y. A Correlational Analysis of Tethered Swimming, Swim Sprint Performance and Dry-land Power Assessments. Int. J. Sports Med. 2016, 37, 211-218. [CrossRef]

15. Garrido, N.; Marinho, D.A.; Barbosa, T.M.; Costa, A.M.; Silva, A.J.; Pérez-Turpin, J.A.; Marques, M.C. Relationships between dry land strength, power variables and short sprint performance in young competitive swimmers. J. Hum. Sport Exerc. 2010, 5, 10. [CrossRef]

16. Marinho, D.A.; Neiva, H.P.; Branquinho, L.; Ferraz, R. Anthropometric characterization and muscle strength parameters in young female swimmers at national level: The relationship with performance in the 50m freestyle. J. Hum. Sport Exerc. 2021, 16, S295-S306. [CrossRef]

17. Bishop, C.; Read, P.; Bromley, T.; Brazier, J.; Jarvis, P.; Chavda, S.; Turner, A. The Association Between Interlimb Asymmetry and Athletic Performance Tasks: A Season-Long Study in Elite Academy Soccer Players. J. Strength Cond. Res. 2020. [CrossRef] [PubMed]

18. Yeung, W.V.; Bishop, C.; Turner, A.N.; Maloney, S.J. Does a Loaded Warm-Up Influence Jump Asymmetry and Badminton-Specific Change of Direction Performance? Int. J. Sports Physiol. Perform. 2021, 1-7. [CrossRef]

19. Madruga-Parera, M.; Bishop, C.; Fort-Vanmeerhaeghe, A.; Beltran-Valls, M.R.; Skok, O.G.; Romero-Rodríguez, D. Interlimb Asymmetries in Youth Tennis Players: Relationships With Performance. J. Strength Cond. Res. 2020, 34, 2815-2823. [CrossRef]

20. Clark, L.D.D.; Bishop, C.; Maloney, S.J. Relationships between jumping asymmetries and performance in skateboarders. J. Aust. Strength Cond. 2021, 29, 437-453.

21. Bishop, C.; Welden, A.; Hughes, J.; Brazier, J.; Loturco, I.; Turner, A.; Read, P. Seasonal Variation of Physical Performance and Inter-limb Asymmetry in Professional Cricket Athletes. J. Strength Cond. Res. 2021. Publish Ahead of Print. [CrossRef] 
22. Bishop, C.; Perez-Higueras Rubio, M.; Gullon, I.L.; Maloney, S.; Balsalobre-Fernandez, C. Jump and Change of Direction Speed Asymmetry Using Smartphone Apps: Between-Session Consistency and Associations With Physical Performance. J. Strength Cond. Res. 2020. [CrossRef] [PubMed]

23. WHO. The Health of Youth; World Health Organization: Geneva, Switzerland, 1989.

24. Viera, A.J.; Garrett, J.M. Understanding interobserver agreement: The kappa statistic. Fam. Med. 2005, 37, 360-363. [PubMed]

25. Cormack, S.J.; Newton, R.U.; McGuigan, M.R.; Doyle, T.L. Reliability of measures obtained during single and repeated countermovement jumps. Int. J. Sports Physiol. Perform. 2008, 3, 131-144. [CrossRef] [PubMed]

26. Koo, T.K.; Li, M.Y. A Guideline of Selecting and Reporting Intraclass Correlation Coefficients for Reliability Research. J. Chiropr. Med. 2016, 15, 155-163. [CrossRef]

27. Hopkins, W.G.; Marshall, S.W.; Batterham, A.M.; Hanin, J. Progressive statistics for studies in sports medicine and exercise science. Med. Sci. Sports Exerc. 2009, 41, 3-13. [CrossRef] [PubMed]

28. Lockie, R.G.; Callaghan, S.J.; Berry, S.P.; Cooke, E.R.; Jordan, C.A.; Luczo, T.M.; Jeffriess, M.D. Relationship between unilateral jumping ability and asymmetry on multidirectional speed in team-sport athletes. J. Strength Cond. Res. 2014, 28, 3557-3566. [CrossRef] [PubMed]

29. McCubbine, J.; Turner, A.; Dos'Santos, T.; Bishop, C. Reliability and measurement of inter-limb asymmetries in four unilateral jump tests in elite youth female soccer players. Prof. Strength Cond. J. 2018, 49, 7-12.

30. Bishop, C. Interlimb Asymmetries: Are Thresholds a Usable Concept? Strength Cond. J. 2021, 43, 32-36. [CrossRef]

31. Cohen, J. A Coefficient of Agreement for Nominal Scales. Educ. Psychol. Meas. 1960, 20, 37-46. [CrossRef]

32. Bishop, C.; Lake, J.; Loturco, I.; Papadopoulos, K.; Turner, A.; Read, P. Interlimb Asymmetries: The Need for an Individual Approach to Data Analysis. J. Strength Cond. Res. 2021, 35, 695-701. [CrossRef] [PubMed]

33. Loturco, I.; Pereira, L.A.; Kobal, R.; Abad, C.C.C.; Komatsu, W.; Cunha, R.; Arliani, G.; Ejnisman, B.; Pochini, A.C.; Nakamura, F.Y.; et al. Functional Screening Tests: Interrelationships and Ability to Predict Vertical Jump Performance. Int. J. Sports Med. 2018, 39, 189-197. [CrossRef]

34. West, D.J.; Owen, N.J.; Cunningham, D.J.; Cook, C.J.; Kilduff, L.P. Strength and power predictors of swimming starts in international sprint swimmers. J. Strength Cond. Res. 2011, 25, 950-955. [CrossRef]

35. Morouço, P.G.; Marinho, D.A.; Fernandes, R.J.; Marques, M.C. Quantification of upper limb kinetic asymmetries in front crawl swimming. Hum. Mov. Sci. 2015, 40, 185-192. [CrossRef] [PubMed]

36. Sanders, R.H. How to asymmetries affect swimming performance? J. Swim. Res. 2013, 21, 1-6.

37. Exell, T.A.; Irwin, G.; Gittoes, M.J.; Kerwin, D.G. Implications of intra-limb variability on asymmetry analyses. J. Sports Sci. 2012, 30, 403-409. [CrossRef] [PubMed]

38. Pérez-Castilla, A.; García-Ramos, A.; Janicijevic, D.; Miras-Moreno, S.; De la Cruz, J.C.; Rojas, F.J.; Cepero, M. Unilateral or Bilateral Standing Broad Jumps: Which Jump Type Provides Inter-Limb Asymmetries with a Higher Reliability? J. Sports Sci. Med. 2021, 20, 317-327. [CrossRef] [PubMed] 